\title{
What are the choices facing first-time entrants to tertiary education?
}

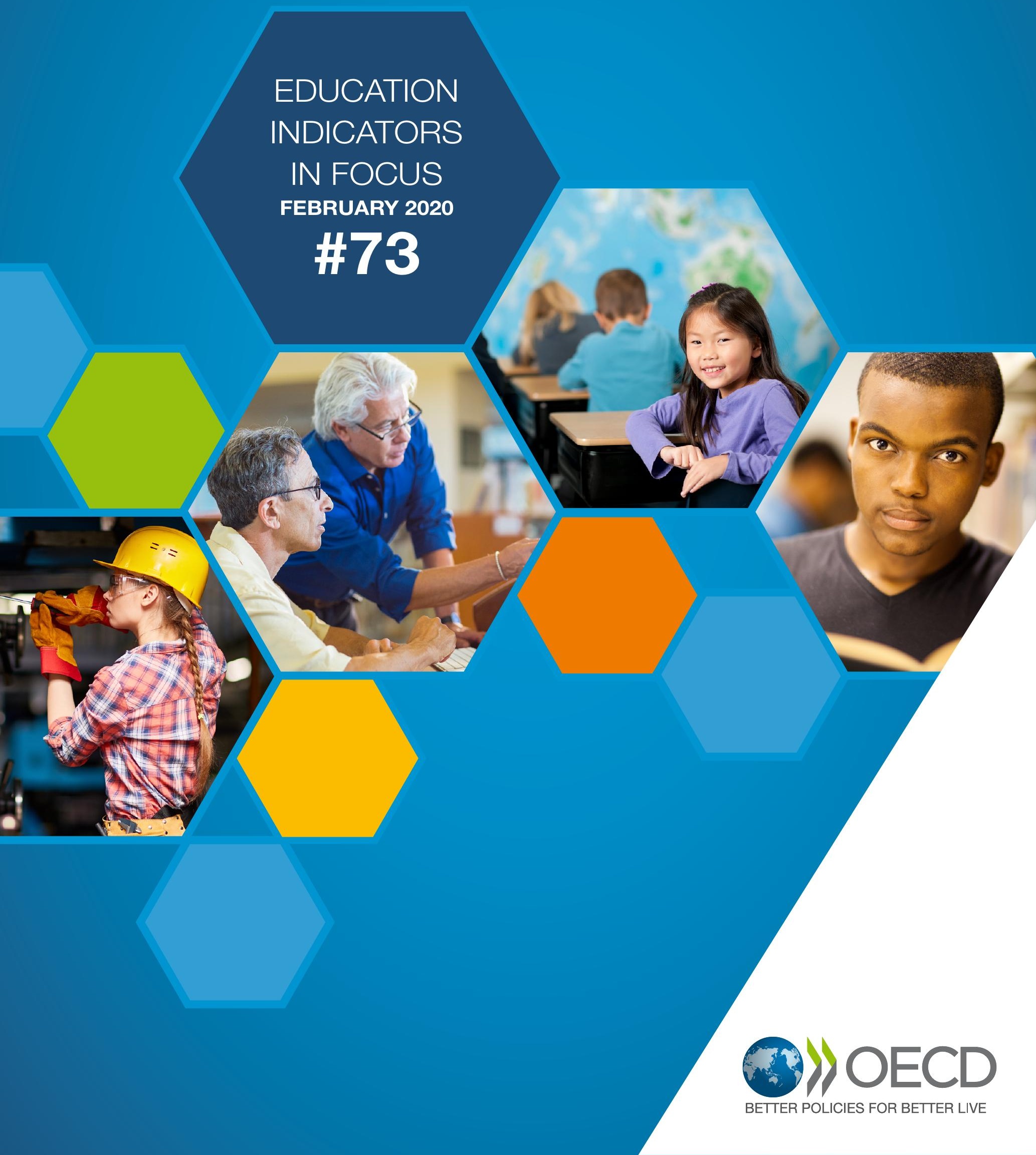


- The field of study chosen by entrants to tertiary education will affect their chances of employment and their future earnings, although not to the extent that some may imagine. Across OECD countries, the average employment rate for tertiary graduates ranges from $90 \%$ for those who studied information and communication technologies to $83 \%$ for arts and humanities, social sciences, journalism and information.

- The level of tuition fees students pay and the level of financial support they receive will depend on where they study. The average (or most common) annual tuition fees range from zero (in public institutions in several OECD countries) to USD 29478 (in independent private institutions in the United States). On average, the financial returns to graduates from tertiary education far outweigh the private costs to them.

- The criteria used to assess applicants' suitability for a programme of study vary greatly. In most OECD countries they will have to pass examinations in order to enrol but beyond this, there is little consistency in selection approaches. Interviews, application letters and grade point averages from secondary school are all used to some extent in different countries.

Many factors will influence upper secondary graduates' decisions to enter tertiary education, including their economic, social and cultural background and their individual interests, motivation and skills. Applicants will use different heuristics to make their decision and will place greater or lesser importance on different outcomes, but they will always have imperfect information about the implications of the decisions they make. New entrants cannot assess with any certainty their chances of succeeding in a given programme of study or whether the labour market will want the skills and knowledge they will have acquired when they graduate. Despite these uncertainties, however, a tertiary education remains a safe investment.

Focusing on factors that have an economic perspective, first-time entrants to tertiary education have to make interconnected decisions about their field of study, the fees they will pay and the application requirements they are prepared to face. Their choice of field of study has implications for their employment prospects and future earnings. Debts incurred whilst studying may restrict future choices about their career and where they live. Nor are applicants completely free to choose the institution or field of study that interests them most, but instead have to demonstrate aptitude through some combination of examinations, secondary school performance, interviews and application letters.

\section{Fields of study affect tertiary students' future earnings and employment rates}

In many cases, new entrants to tertiary education will be moving from a broad secondary curriculum to a much narrower field of study. At tertiary level, the broad fields of study most often associated with the highest employment rates are engineering, manufacturing and construction; and information and communication technologies (ICT). ICT graduates have an employment rate of 90\% on average across OECD countries compared to $83 \%$ for those who studied arts and humanities, social sciences, journalism and information, a gap of 7 percentage points which is substantial but may not be as large as many perceive it (Figure 1). Virtually all OECD countries have a similar gap between these two broad fields of study to some extent.

Their choice of field of study may also affect tertiary graduates' future earnings. Those who studied the broad fields of education or arts and humanities, social sciences, journalism and information can expect to earn less than those who studied engineering, manufacturing and construction or ICT. For example, in Germany, tertiary graduates who studied education earn 30\% more than those with only an upper secondary education but those who studied engineering, manufacturing and construction earn $116 \%$ more.

Many countries place restrictions on the number of students who can enter some or all fields of study. Among the 36 OECD and partner countries with available data, 25 restrict the number of student places in public institutions by field of study. This is less common in independent private institutions. These restrictions can be used as a way to adjust the number of graduates to meet labour-market needs, but might also reflect limits on the number of students institutions can absorb.

These restrictions mean that many applicants are choosing their fields of study in systems where the number of places is limited by government policy or institutions' decisions. It may be obvious to applicants that the fields of study that lead to better-paid professions (medicine, law, business administration) will be popular choices. However it may be less clear whether there will be more places available in the natural sciences or in engineering. Applicants also have to consider not just their chances of securing a place in a given field of study but how likely they are to succeed in it. After all, they will only enjoy the benefits in terms of employment rates and earnings after they have graduated from their tertiary programme.

\footnotetext{
1 Values reported in equivalent US dollars (USD) have been converted using purchasing power parities (PPPs) for gross domestic product (GDP).
} 
Figure 1 / Employment rates of tertiary-educated adults, by field of study (2018) Percentage of employed 25-64 year-olds among all 25-64 year-olds

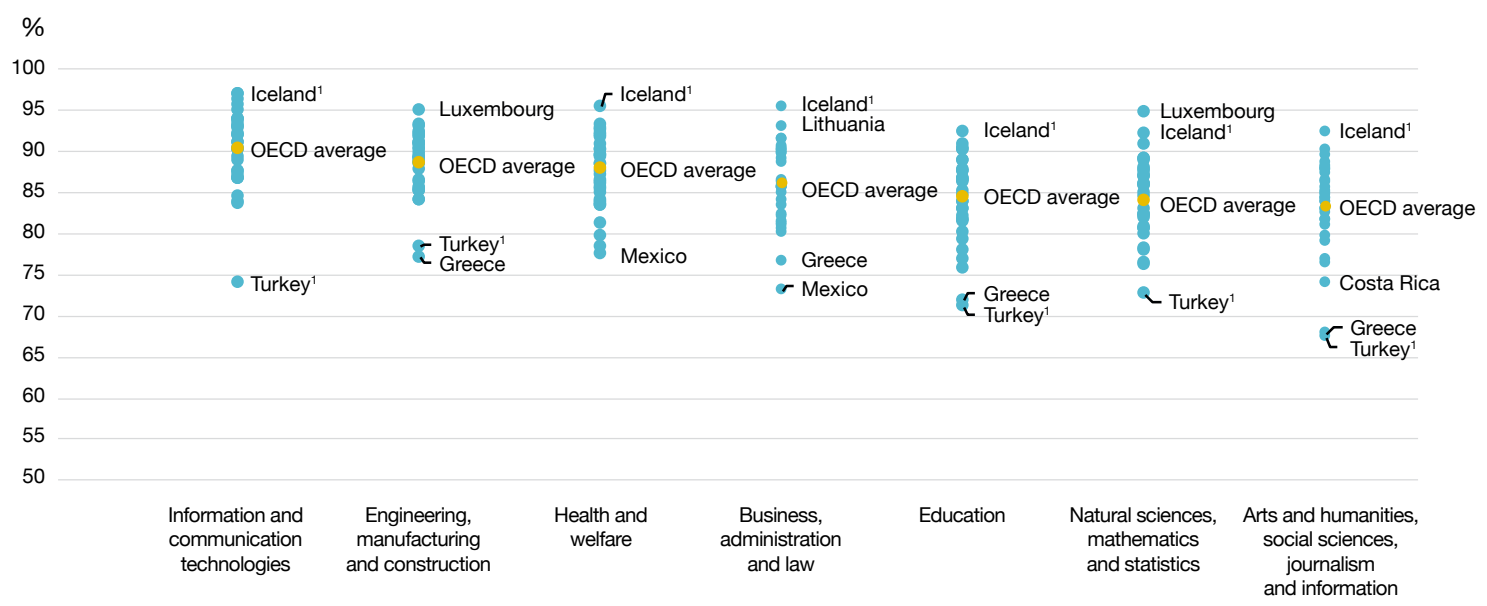

1. Year of reference differs from 2018. Please see Education at a Glance 2019 for details Fields of study are ranked in descending order of the OECD average employment rates Source: OECD (2019 $\left.{ }_{[1]}\right)$ Education at a Glance 2019: OECD Indicators, https://doi.org/10.1787/f8d7880d-en

\section{Tuition fees differ widely within and across countries}

The costs associated with tertiary education are a major factor for upper secondary graduates deciding whether to continue their studies. These costs include tuition fees as well as other direct and indirect costs.

The tuition fees charged by institutions vary significantly between countries (Figure 2). In about one-third of countries, public institutions do not charge any tuition fees for national students enrolled in bachelor's or equivalent programmes. In another third of countries, tuition fees for these students are low or moderate (below USD 2600 per year). In the remaining third, they are high, ranging from USD 3000 per year to over USD 9000.

Figure 2 / Minimum, maximum and average (or most common) annual tuition fees charged by public institutions for national students at bachelor's or equivalent level (2017/18) Annual tuition fees charged to full-time national students, in equivalent USD converted using PPPs for GDP
Average (or most common tuition fee)
- Minimum
$\Delta$ Maximum

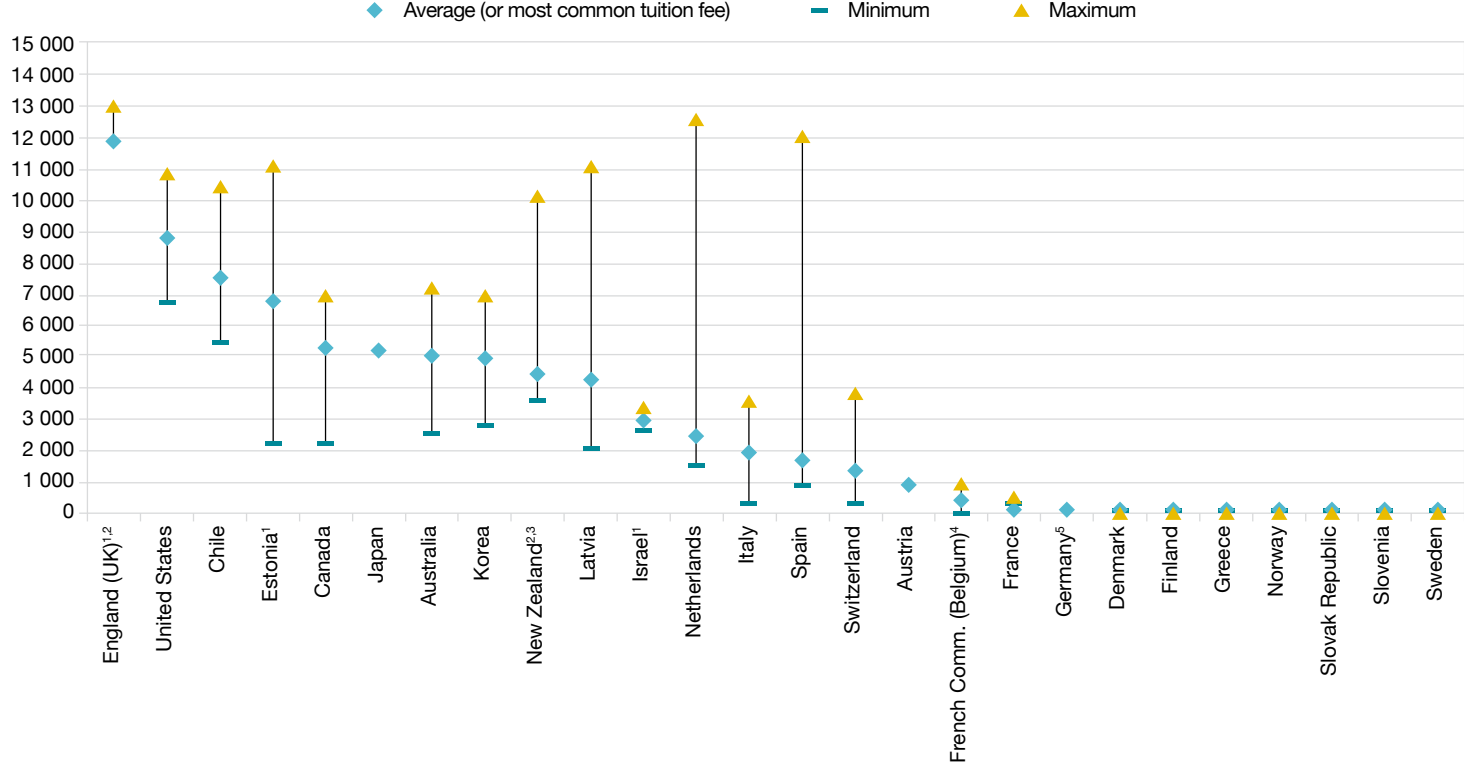

Note: The year of reference may differ across countries and economies. Please see Education at a Glance 2019 Annex 3 for details.

1. Data are presented for government-dependent institutions instead of public institutions.

2. Short-cycle tertiary programmes are included in bachelor's or equivalent programmes.

3. Estimates include universities only and exclude some programmes. Please see Education at a Glance 2019 for details.

4. Government-dependent private institutions are included in public institutions.

5. Tuition fees are presented for total tertiary education instead of bachelor's or equivalent level. Tuition fees correspond to national and foreign students. Only academic programmes are included.

Countries and economies are ranked in descending order of annual average (or most common) tuition fees.

Source: OECD (2019 $\left.{ }_{[1]}\right)$, Education at a Glance 2019: OECD Indicators, https://doi.org/10.1787/f8d7880d-en. 
However, even in countries with high tuition fees, the financial benefits to individuals of graduating from tertiary education can far outweigh the costs. In fact, in all OECD countries there are strongly positive net financial returns from attaining tertiary education compared to an upper secondary education, averaging USD 295900 for a man and USD 227600 for a woman. The returns vary greatly between countries, fields of study and institutions. This variation may dissuade some from studying at tertiary level, particularly if there is limited access to financial support.

In some OECD countries, students have to decide whether to attend a public institution (which tend to have lower tuition fees) or an independent private institution (which tend to have higher tuition fees). The difference in fees can be quite large. For example, in the United States the annual tuition fees for a bachelor's or equivalent programme are USD 8804 per year in public institutions compared to USD 29748 per year in independent private institutions. Students have to decide whether the benefits (financial or otherwise) from attending an independent private institution outweigh the additional costs.

However, not all students in OECD countries face such a choice. The size of the independent private sector varies substantially between countries. In countries such as Latvia, Portugal and the United States between one-fifth and one-third of students (bachelor's or equivalent) are enrolled in independent private institutions. In Chile, Japan and Korea the figure is over 60\%. There are several OECD countries or economies with no independent private institutions enrolling students in bachelor's or equivalent degree programmes: Canada, Finland, Greece, Sweden and England (United Kingdom).

Students may also wish to study abroad. However, foreign students are often charged more than domestic students for the same programme at the same institution. Students travelling abroad to study might also not get the same financial support they would have received if they stayed at home. Both of these considerations mean fewer students are likely to make this choice then would be the case if these barriers were removed. However, many students are clearly still motivated to study abroad and this may be because there is financial support on offer, or because they have a wider choice of programmes or fewer restrictions on the number of students.

\section{Admissions systems vary greatly between countries}

The process for applying to tertiary education varies greatly between OECD countries. Education systems all differ in how centralised the process is, the number of preferences applicants can specify, the number of offers they can receive and the criteria used to select students.

In some countries applicants apply directly to institutions while in others they apply through a centralised system (or some combination of the two). Among the OECD and partner countries with available data, 16 allow public institutions to receive applications directly. A further 11 have a mixed centralised and direct application system, whilst the remaining 10 have a centralised system.

In many countries with centralised systems, applicants are restricted in the number of preferences they can specify, ranging from 2 in Brazil to 24 in France and Turkey. The only countries with centralised or combined application systems that place no limit on the number of preferences are Greece, Italy and New Zealand.

Applicants may also be restricted in the number of offers they may receive. In centralised systems it is common to only allow one offer to be made to an applicant. The Netherlands and the Russian Federation allow three offers to be made while Australia, Canada, Italy and Korea place no such limits.

Applicants to independent private institutions are far less likely to face these kinds of restrictions. Only 10 countries have centralised application systems for independent private institutions, compared to 18 countries that allow applications direct to institutions. Where there is some form of centralised system, the restrictions on the number of preferences and offers that can be made are similar to those for public institutions. 


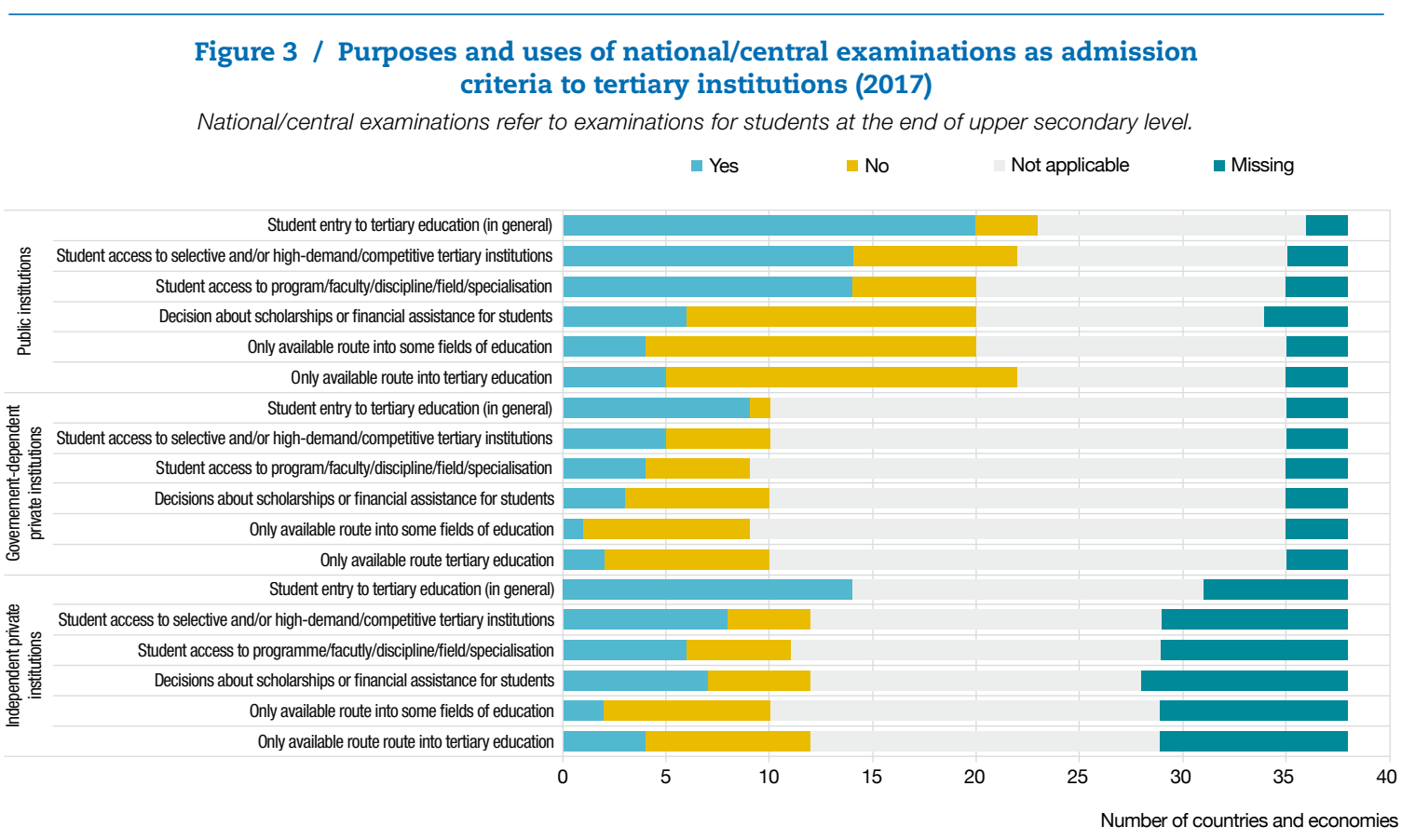

Source: OECD (2019 $\left.{ }_{[2]}\right)$, Education at a Glance 2019: OECD Indicators, https://doi.org/10.1787/f8d7880d-en.

Applicants to a tertiary programme can expect to be asked to demonstrate their suitability in a variety of ways. This means their choice of programme and/or institution is likely to be influenced by the application requirements and process. National or central examinations are the most common criteria for assessing applicants, but their use is not universal (Figure 3). Among the 26 OECD and partner countries with information on admission systems for public institutions, 21 use national or central examinations. These examinations assess the candidates' performance at one point in time, typically at or towards the end of upper secondary education.

Applicants may also be asked to supply their grade point averages (GPAs) from secondary school. The use of GPAs can mean that applicants are assessed over several years. GPAs are used by public institutions in 19 OECD and partner countries among the 29 with available information.

Applicants may also be asked to attend an interview. These are used by public institutions in 20 OECD and partner countries compared to seven who do not use them. Some countries use other criteria such as application letters, work experience and applicants' family income, but these are much less widely used than examinations, GPAs and interviews. The importance placed on the different criteria varies by country but broadly, in public institutions, GPAs are more important than interviews.

It is somewhat surprising that such big differences exist between countries in application systems despite ever-rising international student mobility. Over the last 20 years the number of mobile students enrolled in tertiary education programmes worldwide has expanded massively. It rose from 2 million in 1998 to 5.3 million in 2017, growing at an average annual rate of 5\% among OECD countries. However, the application processes and the criteria used to select students remain very heterogeneous. It is not clear that applicants with some experience of one system will be able to navigate another. 


\section{The bottom line}

First-time entrants to tertiary education are required to make interconnected decisions about their field of study, the fees they will pay and the application requirements they are prepared to face. Their choice of programme and institution will be influenced by the costs and entry criteria. The decisions they make about what to study and where will have a long-term impact on their earnings and employment prospects.

\section{REFERENCES :}

[1] OECD (2019), Education at a Glance 2019: OECD Indicators, OECD Publishing, Paris, https://doi. org/10.1787/f8d7880d-en.

VISIT

www.oecd.org/education/education-at-a-glance-19991487.htm

Education Indicators in Focus (previous issues)

PISA in Focus

Teaching in Focus

How has women's participation and fields of study choice in higher education evolved over time?

\section{CONTACT:}

Bruce Golding (bruce.golding@oecd.org)

Photo credit: @ Christopher Futcher / iStock; @ Marc Romanelli / Gettyimages; @ michaeljung / Shutterstock; @ Pressmaster / Shutterstock This work is published under the responsibility of the Secretary-General of the OECD. The opinions expressed and arguments employed herein do not necessarily reflect the official views of OECD member countries.

This document, as well as any data and any map included herein, are without prejudice to the status of or sovereignty over any territory, to the delimitation of international frontiers and boundaries and to the name of any territory, city or area.

The statistical data for Israel are supplied by and are under the responsibility of the relevant Israeli authorities. The use of such data by the OECD is without prejudice to the status of the Golan Heights, East Jerusalem and Israeli settlements in the West Bank under the terms of international law. 